\title{
A case of left ventricular apical thrombus induce embolic stroke in patient with stress cardiomyopathy
}

Seong Soon Kwon ${ }^{1}$, Gahyoung Kim ${ }^{1}$, Shin Gil Kim ${ }^{1}$, Kyung Bok Lee ${ }^{1}$, and byoung-won Park $^{2}$

${ }^{1}$ Soonchunhyang University Hospital Seoul

${ }^{2}$ Affiliation not available

September 25, 2021

\begin{abstract}
We report a case of left ventricular apical thrombus induce embolic stroke in patient with stress cardiomyopathy. In this case, although we initiated anticoagulant treatment after finding apical thrombus on time, stroke occurred. However, favorable clinical results were achieved with prompt percutaneous mechanical thrombectomy after early suspicion and accurate diagnosis. This case emphasized the need for a follow-up echocardiography during SCMP recovery period to evaluate possible complications such as LV thrombus.
\end{abstract}

\section{Hosted file}

Manuscript.doc available at https://authorea.com/users/437126/articles/538985-a-caseof-left-ventricular-apical-thrombus-induce-embolic-stroke-in-patient-with-stresscardiomyopathy

\section{Hosted file}

Figure1.pptx available at https://authorea.com/users/437126/articles/538985-a-case-of-leftventricular-apical-thrombus-induce-embolic-stroke-in-patient-with-stress-cardiomyopathy

\section{Hosted file}

Figure2.pptx available at https://authorea.com/users/437126/articles/538985-a-case-of-leftventricular-apical-thrombus-induce-embolic-stroke-in-patient-with-stress-cardiomyopathy 